\title{
Inulin and oligofructose modulate lipid metabolism in animals: review of biochemical events and future prospects
}

\author{
N. M. Delzenne*, C. Daubioul, A. Neyrinck, M. Lasa and H. S. Taper \\ Unit of Pharmacokinetics, Metabolism, Nutrition and Toxicology, PMNT-7369 School of Pharmacy Université Catholique \\ de Louvain, Avenue Mounier, 73 B-1200 Brussels, Belgium
}

\begin{abstract}
Inulin and oligofructose, besides their effect on the gastro-intestinal tract, are also able to exert 'systemic' effect, namely by modifying the hepatic metabolism of lipids in several animal models. Feeding male Wistar rats on a carbohydrate-rich diet containing $10 \%$ inulin or oligofructose significantly lowers serum triacylglycerol (TAG) and phospholipid concentrations. A lower hepatic lipogenesis, through a coordinate reduction of the activity and mRNA of lipogenic enzymes is a key event in the reduction of very low-density lipoprotein-TAG secretion by oligofructose. Oligofructose is also able to counteract triglyceride metabolism disorder occurring through dietary manipulation in animals, and sometimes independently on lipogenesis modulation: oligofructose reduces post-prandial triglyceridemia by $50 \%$ and avoids the increase in serum free cholesterol level occurring in rats fed a Western-type high fat diet. Oligofructose protects rats against liver TAG accumulation (steatosis) induced by fructose, or occurring in obese Zucker fa/fa rats. The protective effect of dietary inulin and oligofructose on steatosis in animals, would be interesting, if confirmed in humans, since steatosis is one of the most frequent liver disorders, occurring together with the plurimetabolic syndrome, in overweight people. The panel of putative mediators of the systemic effects of inulin and oligofructose consists in either modifications in glucose/insulin homeostasis, the end-products of their colonic fermentation (i.e. propionate) reaching the liver by the portal vein, incretins and/or the availability of other nutrients. The identification of the key mediators of the systemic effects of inulin and oligofructose is the key to identify target function(s) (or dysfunction(s)), and finally individuals who would take an advantage of increasing their dietary intake.
\end{abstract}

Fructans: Triacylglycerol: Steatosis: Rat: Short-chain fatty acids

\section{Systemic effects of dietary inulin and oligofructose: their influence on lipid metabolism}

In lean rats or hamsters fed a diet supplemented with inulin or oligofructose, a decrease in serum triglyceridemia (both in fed and fasted state) has consistently been reported in several studies (Fiordaliso et al. 1995; Kok et al. 1996a; Delzenne \& Kok, 1998; Trautwein et al. 1998). Especially the fact that feeding male Wistar rats a diet supplemented with oligofructose $(10 \%$ in the diet) significantly lowers serum triacylglycerol and phospholipid concentrations (Fiordaliso et al. 1995). The hypotriglyceridemia is mostly due to a decrease in the concentration of plasma very low-density lipoproteins (VLDL, Kok et al. 1996a). This effect is likely to result from a decrease in the hepatic synthesis of triglycerides rather than to an increase in the catabolism of triglyceride-rich lipoproteins (Delzenne \&
Kok, 1999). Hepatocytes isolated from oligofructose-fed rats have a slightly lower capacity to esterify $\left[{ }^{14} \mathrm{C}\right]$-palmitate into triglycerides, but a $40 \%$ decreased capacity to synthesize triglycerides from $\left[{ }^{14} \mathrm{C}\right]$-acetate (Fiordaliso et al. 1995). These data support the hypothesis that a decreased de novo lipogenesis in the liver, through a coordinate reduction of the activity of all lipogenic enzymes, is a key event in the reduction of VLDL-TG secretion in oligofructose-fed rats: in fact, the activities of acetylCoA carboxylase, fatty acid synthase (FAS), malic enzyme, ATP citrate lyase and glucose-6-phosphate dehydrogenase are decreased by about $50 \%$. This coordinated decrease of all enzymes, together with the lower activity of enzymes like FAS, which are only regulated through modifications of protein and mRNA content, supports the hypothesis that oligofructose administration could modify lipogenic enzyme gene expression as shown by the lower FAS

\footnotetext{
Abbreviations: FAS, fatty acid synthase; GIP, glucose-dependent insulinotropic peptide; GLP-1, glucagon-like peptide 1; TAG, triacylglycerol; VLDL, very low-density lipoproteins.

Note: For the definition of the terms inulin and oligofructose please refer to the introductory paper (p. S139) and its footnote.

* Corresponding author: Dr N. Delzenne, tel +32 2764 7369, fax +32 2764 7359, email Delzenne@pmnt.ucl.ac.be
} 


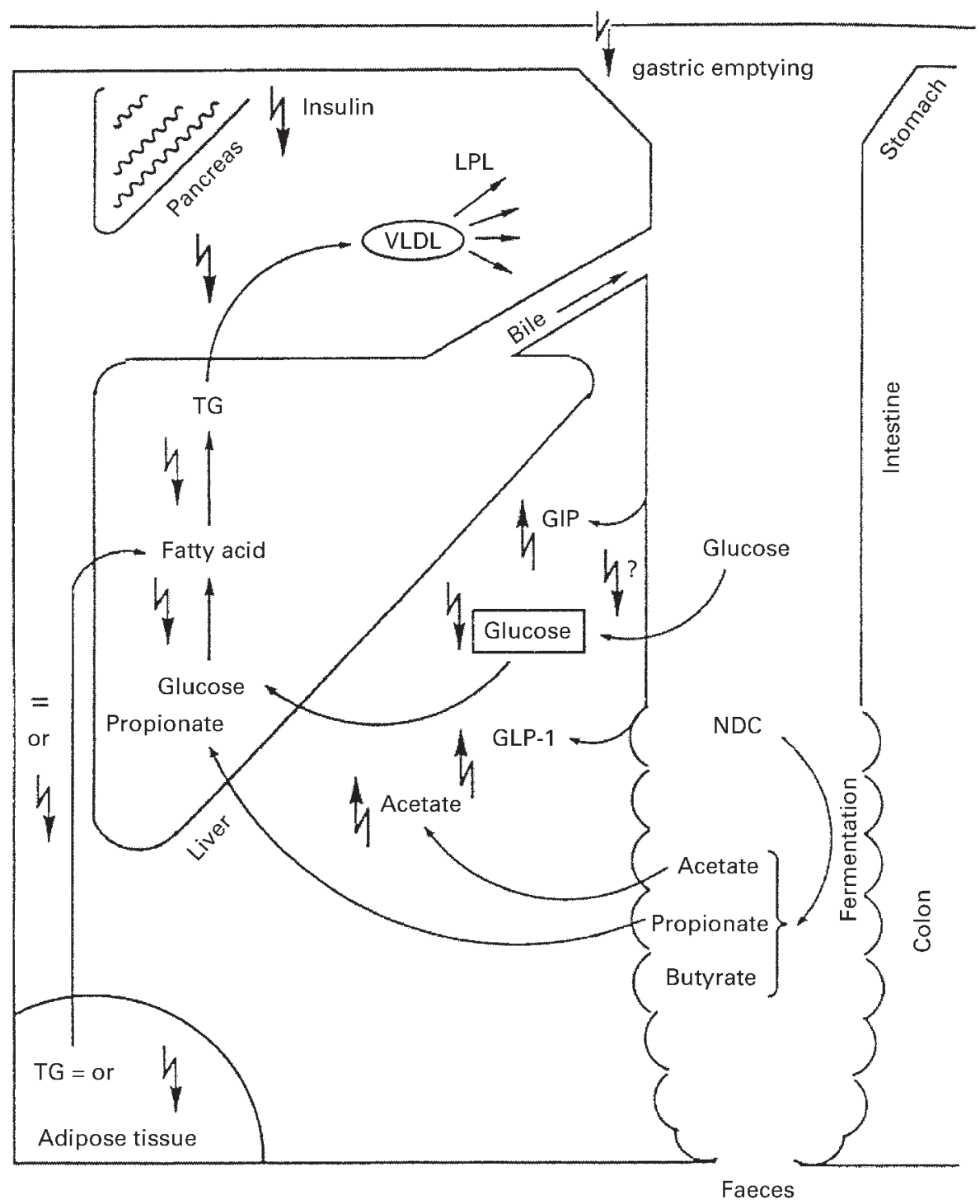

Fig. 1. From Delzenne \& Williams (1999). Putative mechanisms involved in the modulation of lipid metabolism by dietary inulin and oligofructose in rats, including effects on gastric emptying and glucose absorption, production of short-chain carboxylic acids (acetate, propionate, butyrate), secretion of incretins, and subsequent actions on liver, adipose tissue, and pancreatic insulin output.

mRNA concentration in the liver tissue of oligofructosefed animals using a northern blot analysis (Delzenne \& Kok, 1999).

But oligofructose is also able to positively modulate triglyceride metabolism disorder caused by dietary manipulation in animals. When added to a diet composed of $10 \%$ lard, $4 \%$ corn oil, and $0.15 \%$ cholesterol for 3 weeks, it reduced the post-prandial triglyceridemia by $50 \%$ and avoided the increase in the free cholesterol level in the serum induced by the high fat diet. These last results suggest that oligofructose is also able to decrease serum TAG through an extra-hepatic mechanism, namely by enhancing triglyceride-rich lipoprotein catabolism (Kok et al. 1998a). The hypotriglyceridemia effect of oligofructose supplementation was also shown in hamsters fed a high fat/cholesterol diet (Trautwein et al. 1998).

When fructose is added to the drinking water of rats for $48 \mathrm{~h}$, there is an increase in TAG concentration in the liver tissue, but chronic feeding of the fructose-treated rats with oligofructose protected them against liver TAG accumulation (Kok et al. 1996b). The lower lipogenic capacity of the liver could be one of the key events in such a protection since, even after the fructose load, FAS activity remained significantly lower in the oligofructose-fed rats. However, despite its protective effect on the liver, oligofructose was not able to prevent the fructose-induced hypertriglyceridemia, suggesting that oligofructose feeding could not counteract the fructose-induced change in VLDL-TAG clearance.

In a more recent study, it has been shown that dietary enrichment with oligofructose can reduce both the fat mass development and the hepatic steatosis occurring in obese Zucker fa/fa rats (Daubioul et al. 2000). This 'hepatoprotective' effect of oligofructose was not accompanied by any significant modifications in post-prandial serum TAG concentration. However, only a modest effect on 
hepatic lipogenic enzymes was observed. More recent studies also show that Zucker rats fed $10 \%$ of a mixture of inulin + oligofructose, also exhibited a lower body weight gain, a decrease in visceral and epididymal fat mass, and a marked protective effect against liver steatosis, as compared to controls. Microcrystalline cellulose (a nondigestible carbohydrate, which is only poorly fermented in the caeco-colon of rats), however, was unable at the same dose $(10 \%)$, to modify lipid homeostasis in obese Zucker rats (Daubioul, personal communication). These last results support the fact that a decrease in the weight of visceral fat mass (and/or the subsequent decrease in non-esterified fatty acid availability) might constitute an important metabolic event in the regulation of hepatic fatty acid metabolism, at least in obese animals. As a putative mechanism by which inulin and oligofructose might decrease body weight and fat mass, it is worth mentioning that a transient 'satietogenic' effect leading to a decrease in food intake has been observed during the first 3 weeks of the treatment of obese Zucker rats fed oligofructose (Daubioul et al. 2000). Such an effect of dietary oligofructose on food (and calorie) intake has never been observed in nonobese animals.

\section{What are the putative links between the gastrointestinal effects of inulin and oligofructose, and their systemic effect on lipid homeostasis? (Fig. 1)}

\section{Modifications of glucose and/or insulin levels: which relationship with de novo lipogenesis?}

Dietary modulation of lipogenesis is often linked to such physiological changes. Indeed, the induction of lipogenic enzymes by glucose, occurring via an increased gene transcription, is potentiated by insulin (Girard et al. 1997). The association between glycemia/insulinemia and triglyceride has also been demonstrated for resistant starch which, in rats, decreases serum triglyceride concentration, reduces fatty acid synthase activity by $20 \%$, and concomitantly lowers post-prandial insulinemia (Takase et al. 1994; Morand et al. 1994). The effects of inulin/oligofructose on glycemia and insulinemia are not yet fully understood and available data are sometimes contradictory indicating that these effects may depend on physiological (fasting $v$. postprandial state) or disease (diabetes) conditions: oligofructose given at the dose of $10 \%$ in the diet of male Wistar rats for 30 days, reduces post prandial insulinemia by $26 \%$ (Kok et al. 1998b). However, the glycemic response during a glucose-tolerance test after overnight fasting is identical in control and oligofructose-fed rats (Kok et al. 1998b; Daubioul et al. 2000). In streptozotocin-treated (diabetic) rats, feeding a diet containing $20 \%$ oligofructose for 2 months decreases post-prandial glycemia, despite a lack of modification of the glycemic/insulinemic response to a saccharose or maltose load (Brichard, 1997).

Even though they are not digested in the upper part of the gastro-intestinal tract, inulin/oligofructose may, like many other dietary fibres, influence the absorption of macronutrients, especially carbohydrates either by delaying gastric emptying and/or shortening small intestinal transit time. Indeed it has been reported that feeding rats a diet containing 10 and $20 \%$ oligofructose (from sucrose) for 6 weeks shortens mouth to anus transit time by 25 to $50 \%$ respectively, a result which suggests a dose-dependent effect (Oku et al. 1984). It must be underlined however, that inulin/oligofructose do not have a high viscous effect like other non starch polysaccharides. The contribution of insulin and glucose homeostasis in the lower hepatic lipogenesis in oligofructose-fed rats may not be discarded, but additional studies need to be performed in order to clarify how, and when oligofructose supplementation modulates glucose and insulin secretion and response.

\section{The role of metabolites produced in the caeco-colon in the regulation of lipid metabolism}

Among the molecules produced by intestinal bacteria following oligofructose and inulin fermentation, short-chain carboxylic acids are interesting candidates, since some of them reach the liver through the portal vein (Demigné et al. 1999). The concentration of both acetate and propionate is increased more than 2-fold in the portal serum of oligofructose-fed rats (Roberfroid \& Delzenne, 1998). However, the involvement of short-chain carboxylic acids is, as for cholesterol lowering effect, difficult to prove, as they have an antagonistic effect: propionate has been reported to inhibit fatty acid synthesis (Nishina \& Freeland, 1990; Taskinen, 1993; Demigné et al. 1995; Lin et al. 1995), whereas acetate is a lipogenic substrate. We have recently shown that propionate, at concentrations found in the serum of the portal vein of oligofructose-fed rats $(0.6 \mathrm{mM})$, inhibited the carrier-mediated acetate uptake in cultured isolated hepatocytes, but was unable to modify palmitate or glucose incorporation into esterified fatty acids, at least after short-term incubation (Declerck B, unpublished results). However, propionate, at a concentration of $0.6 \mathrm{mM}$, was able to decrease FAS mRNA concentration in cultured hepatocytes, and could thus constitute a putative mediator of the anti-lipogenic effect of dietary oligofructose. Other molecules are also produced in the caeco-colon, through fermentation of dietary inulin and oligofructose. An increase in the concentration of polyamines like putrescine was observed in the caecum of oligofructose-fed rats, but no modifications of their concentration occurred in the portal vein or the liver. Their role as modulators of lipid metabolism after dietary oligofructose supplementation thus appears equivocal (Delzenne et al. 2000).

Are gut peptides candidates to explain the systemic effect of dietary oligofructose?

Glucose dependent insulinotropic polypeptide (GIP) and glucagon-like peptide-1(7-36)amide (GLP-1) are important mediators, which participate in the regulation of postprandial insulin release. Both peptides are released from endocrine cells in the intestinal mucosa after ingestion of carbohydrates and enhance post-prandial insulin release from the pancreatic beta cells (Morgan, 1996; Drucker et al. 2000). In addition to their insulinotropic effects, 
GIP and GLP-1 are also able, through their binding to specific receptors, to influence glucose and lipid metabolism, at least in the adipose tissue. Both are able to promote insulin-induced glucose uptake and de novo lipogenesis in peripheral adipose tissue. Dependent on its concentration, GIP has been shown to stimulate or inhibit lipolysis in adipocytes, and to stimulate lipoprotein lipase in cultured preadipocytes (Oben et al. 1991; Morgan, 1996). Oligofructose supplementation in the diet of rats has been shown to increase post-prandial serum GIP level (Kok et al. 1998b). The amount of GLP-1 in the caecal tissue was also increased, leading to an increase of GLP-1 concentration in the caecal tissue and in the portal serum (Kok et al. 1998b; Daubioul, unpublished results). Further studies are needed to clarify the metabolic consequences (on lipid metabolism and on glucose/insulin homeostasis) of the modulation of incretins secretion by dietary oligofructose or other non-digestible fermentable carbohydrates.

\section{Conclusions and perspectives}

In view of the results obtained in animals, it appears that supplementing the diet with inulin or oligofructose for a few weeks, leads to pleiotropic and differential modifications of TAG metabolism, depending on the type of diet in which it is incorporated (effect on TAG-rich lipoprotein catabolism in rats fed a fat-rich diet versus an effect on hepatic lipogenesis in rats fed a carbohydraterich diet). The 'functional' consequences of oligofructose feeding also differs with the patho-physiological conditions: a decrease in fat mass and hepatic steatosis, without any effect on triglyceridemia, occurs in obese Zucker rats, whereas a lower triglyceridemia, without any effect on body weight, is often observed in non-obese animals. Knowing the role of hormones and peptides, such as insulin, GLP-1, and GIP as direct or indirect regulators of key enzymes of triglyceride metabolism, their implication in the metabolic events occurring in oligofructose-fed animals needs to be clarified.

The decrease in triglyceride content in the liver tissue, appearing in most of the studies performed so far, requires further investigation. Non alcoholic liver steatosis is a frequent pathology, occurring mainly in overweight and obese people, which has recently been proposed as a new feature of the metabolic syndrome (Cortez-Pinto et al. 1999; Luyckx et al. 2000). It is diagnosed in $86 \%$ of severely obese people (body mass index $>45 \mathrm{~kg} / \mathrm{m}^{2}$ ) (Marceau et al. 1999; Grundy, 2000). Moreover, it should be interesting to analyse the putative effect of inulin and oligofructose on TAG accumulation in other tissues. Indeed, recent data suggest that TAG accumulation occurring in organs other than the liver plays a role in physiological dysfunction(s) linked with obesity. The accumulation of TAG impairs insulin secretion by pancreatic $\beta$-cells, and modulates insulin sensitivity in muscle cells (Koyama et al. 1997; Manco et al. 2000). Could oligofructose feeding modify TAG accumulation in extra-hepatic tissue, as shown in the liver? The effect of inulin and oligofructose on FAS activity and expression has been shown in the liver. A recent study reports that a FAS inhibitor, when it is administrated systemically, promotes satiety in mice (Loftus et al. 2000). Could such an effect be involved in the decrease in body weight occurring in obese Zucker rats, receiving oligofructose in their diet? Or is the effect of on dietary intake linked to GLP-1 production and secretion, since GLP-1 has been proposed as a satietogenic peptide (Christophe, 1998)?

Finally, some studies suggest that inulin and oligofructose are able to impair tumor development in several experimental models. Tumors in the mammary gland, the colon, the prostate and the ovary, exhibiting a high FAS expression and de novo lipogenesis, are often related to a poor prognosis (Milgraum et al. 1997). Could the modulation of substrate availability and hormonal steady-state by dietary inulin and oligofructose be involved in lipid synthesis, and subsequent proliferation of tumor cells?

All these questions open new fields of experimental research relative to the effect of dietary inulin and oligofructose on lipid metabolism. Besides the scientific interest of the questions, the relevance in humans of these effects shown in rats remains to be proven. In that respect, the elucidation of the biochemical mechanism by which nondigestible carbohydrates exert their systemic effects on lipid metabolism will help to clarify the physiological and pathological situations in which the functionality of these nutrients will be useful.

\section{Acknowledgements}

This work supported by EEC: FAIR-CT97-3011/ 'Nutrigene'.

\section{References}

Brichard S (1997) Influence de mesures nutritionnelles sur l'homéostasie glucidique du rat diabétique. Effets bénéfiques des fructo-oligosaccharides et du vanadium. PhD Thesis. Université Catholique de Louvain. Belgium.

Christophe J (1998) Is there appetite after GLP-1 and PACAP? Annals of the New York Academy of Sciences 865, 323-335.

Cortez-Pinto H, Camilo ME, Baptista A, De Oliveira AG \& De Moura MC (1999) Non-alcoholic fatty liver: another feature of the metabolic syndrome? Clinical Nutrition 18, 353-358.

Daubioul C, De Wispelaere L, Taper H \& Delzenne N (2000) Dietary oligofructose lessens hepatic steatosis, but does not prevent hypertriglyceridemia in obese Zucker rats. Journal of Nutrition 130, 1314-1319.

Delzenne N \& Kok N (1998) Effect of non-digestible fermentable carbohydrates on hepatic fatty acid metabolism. Biochemical Society Transactions 26, 228-230.

Delzenne N \& Kok N (1999) Biochemical basis of oligofructoseinduced hypolipidemia in animal models. Journal of Nutrition 129, $1467 \mathrm{~S}-1470 \mathrm{~S}$.

Delzenne N \& Williams C (1999) Actions of non-digestible carbohydrates on blood lipids in humans and animals. In Colonic Microbiota, Nutrition and Health, pp. 213-232 [G Gibson and M Roberfroid, editors]. The Netherlands: Kluwer Academic Publishers.

Delzenne N, Kok N, Deloyer P \& Dandrifosse G (2000) Polyamines as mediators of physiological effects of dietary oligofructose in rats. Journal of Nutrition 130, 2456-2460.

Demigné C, Morand C, Levrat MA, Besson C, Moundras C \& Rémésy C (1995) Effect of propionate on fatty acid and 
cholesterol synthesis and on acetate metabolism in isolated rat hepatocytes. British Journal of Nutrition 74, 209-219.

Demigné C, Remesy C \& Morand C (1999) Short chain fatty acids. In Colonic Microbiota, Nutrition and Health, pp. 55-70 [G Gibson and M Roberfroid, editors]. The Netherlands: Kluwer Academic Publishers.

Drucker D, Lovshin J, Baggio L, Nian M, Adatia F, Boushey R, Liu Y, Saleh J, Yusta B \& Srocchi L (2000) New developments in the biology of the glucagon-like peptides GLP-1 and GLP-2. Annals of the New York Academy of Sciences 921, 226-232.

Fiordaliso M-F, Kok N, Desager J-P, Goethals F, Deboyser D, Roberfroid M \& Delzenne N (1995) Dietary oligofructose lowers triglycerides, phospholipids and cholesterol in serum and very low density lipoproteins of rats. Lipids 30, 163-167.

Girard J, Ferré P \& Foufelle F (1997) Mechanisms by which carbohydrates regulate expression of genes for glycolytic and lipogenic enzymes. Annual Review of Nutrition 17, 325-352.

Grundy SM (2000) Metabolic complications of obesity. Endocrine 13, 155-165.

Kok N, Roberfroid M, Robert A \& Delzenne N (1996a) Involvement of lipogenesis in the lower VLDL secretion induced by oligofructose in rats. British Journal of Nutrition 76, 881-890.

Kok N, Roberfroid M \& Delzenne N (1996b) Dietary oligofructose modifies the impact of fructose on hepatic triacylglycerol metabolism. Metabolism 45, 1547-1550.

Kok N, Taper H \& Delzenne N (1998a) Oligofructose modulates lipid metabolism alterations induced by a fat-rich diet in rats. Journal of Applied Toxicology 18, 47-53.

Kok N, Morgan L, Williams C, Roberfroid M, Thissen JP \& Delzenne N (1998b) Insulin, glucagon-like peptide 1, glucosedependent insulinotropic polypeptide and insulin-like growth factor I as putative mediators of the hypolipidemic effect of oligofructose in rats. Journal of Nutrition 128, 1099-1103.

Koyama K, Chen G, Lee Y \& Unger RH (1997) Tissue triglycerides, insulin resistance, and insulin production: implications for hyperinsulinemia of obesity. American Journal of Physiology 273, E708-713.

Lin Y, Vonk RJ \& Sloof MJ (1995) Differences in propionateinduced inhibition of cholesterol and triacylglycerol synthesis between human and rat hepatocytes in primary culture. British Journal of Nutrition 74, 197-207.

Loftus TM, Jaworsky D, Frehywot G, Townsend C, Ronnett G, Lane M \& Kuhajda F (2000) Reduced food intake and body weight in mice treated with fatty acid synthase inhibitors. Science 288, 2379-2381.
Luyckx F, Lefebvre P \& Scheen A (2000) Non alcoholic steatohepatitis: association with obesity and insulin resistance, and influence of weight loss. Diabetes Metabolism 26, 98-106.

Manco M, Mingrone G, Greco A, Capristo E, Gniuli D, De Gaetano A \& Gasbarrini G (2000) Insulin resistance directly correlates with increased saturated fatty acids in skeletal muscle triglycerides. Metabolism 49, 220-224.

Marceau P, Biron S, Hould F-S, Marceau S, Simara S, Thung S \& Kral J (1999) Liver pathology and the metabolic syndrome X in severe obesity. Journal of Clinical Endocrinology and Metabolism 84, 1513-1517.

Milgraum L, Witters L, Pasternack G \& Kuhajda F (1997) Enzymes of the fatty acid synthesis pathway are highly expressed in in situ breast carcinoma. Clinical Cancer Research 3, 2115-2120.

Morand C, Levrat M, Bzesson C, Demigné C \& Rémésy C (1994) Effect of a diet rich in resistant starch on hepatic lipid metabolism in the rat. Journal of Nutritional Biochemistry 5, $138-144$.

Morgan L (1996) The metabolic role of GIP: physiology and pathology. Biochemical Society Transactions 24, 585-591.

Nishina P \& Freeland R (1990) Effects of propionate on lipid biosynthesis in isolated hepatocytes. Hepatology 16, 1350-1356.

Oben J, Morgan L \& Fletcher J (1991) Effect of the entero-pancreatic hormones, gastric inhibitory polypeptide and glucagonlike polypeptide-1(7-36)amide on fatty acid synthesis in explants of rat adipose tissue. Journal of Endocrinology 130, $267-272$.

Oku T, Tokunaga T \& Hosoya N (1984) Non digestibility of a new sweetener 'Neosugar' in the rat. Journal of Nutrition 114, 1574-1581.

Roberfroid M \& Delzenne N (1998) Dietary fructans. Annual Review of Nutrition 18, 117-143.

Taskinen MR (1993) Hyperinsulinism and dyslipidemias as coronary heart disease risk factors in NIDDM. Advances in Experimental and Medical Biology 334, 295-300.

Takase S, Goda T \& Watanabe M (1994) Monostearylglycerolstarch complex: its digestibility and effects on glycemic and lipogenic responses. Journal of Nutritional Sciences and Vitaminology 40, 23-36.

Trautwein E, Rieckhoff D \& Eebersdobler H (1998) Dietary inulin lowers plasma cholesterol and triacylglycerol and alters bile acid profile in hamsters. Journal of Nutrition 128, 1937-1943. 